\title{
Dossier
}

\section{The Right to Science: Ensuring that Everyone Benefits from Scientific and Technological Progress}

\begin{abstract}
7 he right to enjoy the benefits of scien1 tific progress has long been neglected, both in theory and in practice. Even scholars, advocates, and jurists deeply involved in the human rights field are likely to express uncertainty as to what the right to science concretely requires... if they are even aware of its existence. This article seeks to remedy that obscurity, providing a highly accessible account of the right to science that is both philosophically grounded and concrete. In short, the right to science calls for treating scientific research, scientific knowledge, and technology as global public goods, to be cultivated for the benefit of humanity and made accessible to all, just as with other socioeconomic rights such as education and healthcare. This article then elaborates what that broad vision means for minimum core content. Particular emphasis is given to reconciling the potential tension between the right to science and intellectual property regimes.
\end{abstract}

\section{Résumé}

Te droit de bénéficier du progrès scientiLique et de ses applications a pendant longtemps été négligé, tant en théorie qu'en pratique. Même les chercheurs, avocats ou juristes profondément impliqués dans le domaine des droits de l'homme expriment une incertitude quant à ce que le droit à la science requiert concrètement ... si tant est qu'ils aient connaissance de son existence. Cette contribution a pour but de remédier à cette obscurité en apportant des précisions, tant philosophiques que pratiques, relatives au droit à la science. En résumé, le droit à la science appelle à appréhender la science et la technologie en tant que bien public global, à développer au bénéfice de l'humanité et à rendre accessible à tous, au même titre que d'autres droits économiques, sociaux et culturels tels le droit à la santé ou le droit à l'éducation. Cette contribution élaborera par la suite ce que cette vision large du droit à la science aura comme effet sur le contenu obligatoire minimum de ce droit. L'accent sera ainsi mis sur la réconciliation d'une tension potentielle entre le droit à la science et les régimes de propriété intellectuelle.

\section{5/4 $\left|\begin{array}{r}\text { Journal européen des droits de l'homme } \\ \text { European Journal of Human Rights }\end{array}\right| \mathbf{4} 1$}

This is the author's manuscript of the article published in final edited form as:

Shaver, L. (2015). The Right to Science: Ensuring that Everyone Benefits from Scientific and Technological Progress. 


\section{Introduction and Summary}

$\mathrm{T}$ hinking about the right to science is at once very old and very new. It is old, in the sense that the textual basis for this right, and the debates about its inclusion in the Universal Declaration of Human Rights (UDHR), date back to the 1940s. ${ }^{1}$ During the 1960s and 1970s this debate was rekindled in the context of the Covenant on Economic, Social and Cultural Rights. But in another sense the debate is also still new. The right to science remains today at a very early stage of conceptualization compared to the right to education or the right to health - and even more so compared to freedom of expression or the right to privacy. Even people deeply involved in the human rights field are frequently unaware of the existence of a right to science, much less of its meaning. Thus the right to science is a human right whose conceptual content needs to be both recovered and further developed.

Recognizing this need, the Office of the High Commissioner for Human Rights (OHCHR) organized a Seminar on the Right to Enjoy the Benefits of Scientific Progress and its Applications in October of 2013. ${ }^{2}$ This Seminar implemented one of the recommendations made by Farida Shaheed, the UN Special Rapporteur in the field of Cultural Rights, in her Report to the Human Rights Council the prior year. ${ }^{3}$ Shaheed had suggested a participatory process to improve the conceptual clarity of "the right to science and related obligations," as an area of human rights law that had long been neglected as a matter of both theory and practice. The Seminar proved to be lively and generative, bringing together a global group of experts to share perspectives over two days. This essay reflects some important new insights that came out of that seminar, as well as a later academic workshop hosted by the University of Fribourg, at which the papers of this symposium were presented and developed.

This essay seeks to do two things to contribute to greater conceptual clarity regarding the right to science.

Part II establishes a theoretical foundation for the right through a discussion of its fundamental principles. Toward this end, the discussion emphasizes the animating spirit of science as a public good, with both instrumental and intrinsic value, to be directed toward the service of humanity, guided by values of participation and inclusion. Science and technology have significant power as a means to the end of improving the human situation, but the scientific endeavor also has inherent value as a way in which individuals and communities give expression

\footnotetext{
1 UN General Assembly, Resolution 217 A (III), 10 December 1948, (A/RES/3/217 A). Article 27(1) state that "Everyone has the right...to share in scientific advancement and its benefits."

2 Report of the United Nations High Commissioner for Human Rights the seminar on the right to enjoy the benefits of scientific progress and its applications, presented at the twenty-sixth session of the Human Rights Council (1 April 2014) (A/HRC/26/19)

${ }^{3}$ Report of the Special Rapporteur in the field of cultural rights Ms. Farida Shaheed on the right to enjoy the benefits of scientific progress and its applications, presented at the twentieth session of the Human Rights Council (14 May 2012) (A/HRC/20/26).
} 
to a unique aspect of the human personality, much like the arts and other forms of culture. To bring life to these values, however, not just any science will do. Realizing the human rights potential of the science and technology requires a philosophical and practical commitment to science and technology in service of humanity, rather than in service of state power or private profit. In particular, the human rights approach requires a conception of science and technology as public goods, which must be supported and cultivated and made accessible to all people - as with education and health care. To achieve this goal, scientific norms and innovation policy must consciously prioritize broad public participation in the scientific and technological process, and ensure widespread access to new technologies, particularly for the poor and other vulnerable populations.

Yet it is one thing to talk about the general principles and spirit of the right to science, and quite another to define the specific legal obligations and concrete standards it entails. Particularly in the context of socioeconomic rights, it is often difficult to make this translation from abstract principles to concrete legal obligations. To take a contrasting example, freedom of expression also began its legal life as an abstract principle or aspiration. Over the course of centuries, however, this right has benefitted from extensive advocacy, debate, and clarification. The resulting clarity gives us greater confidence today that we understand what "freedom of expression" actually means: that this human right is more than just a rhetorical claim, but is capable of judicial review and carries specific content... even though reasonable people may disagree about some aspects of that content. This much-needed process of advocacy, debate, and clarification, however, is still at an early stage when it comes to the right to science.

To advance this goal of concretization, Part III then proceeds to speak more specifically about what States must do to honor the right to science, by exploring what "minimum core content" might be attributed to this right. Four conceptually distinct approaches to elaborating the minimum core content of human rights are deployed, seeking to translate the high-level principles elaborated in the first part of the essay into more concrete legal obligations. The discussion begins by highlighting the problematic nature of a "core consensus" approach to defining the content of the right to science, at a time when the right still struggles for recognition. Next, the "normative essence" approach is identified as a more promising method, suggesting a concept of "essential technologies" to which all people should enjoy affordable access. Third, the "minimum obligations" approach focuses more explicitly on the duties of States in respect of the right to science, highlighting universal access to clean water, sanitation, electricity, the Internet, and other essential technological services; academic and Internet freedom; protection against the use of technology to abuse privacy or other human rights; public access to publicly funded research; and intellectual property rules that are adopted through a publicly transparent process enabling an appropriate balancing of interests in protection and in access. Finally, the essay proposes a fourth, "pragmatic approach" to minimum core content, which responds to particular issues 
and challenges of our time. This section discusses the relevance of the right to science to current battles over access to medicines for addressing the HIV/AIDs crisis, other key conflicts between the right to science and the current expansionist trend in regulation of intellectual property, and debates over Internet governance and freedom.

Throughout this work, I will use the phrase "the right to science" rather than the more formal phrase "the Right to Enjoy the Benefits of Scientific Progress and its Applications" or its common abbreviation "REBSP". The task before us is one of promoting dialogue and discussion about this right and advancing conceptual clarity; these goals are best facilitated when we have a simple and straightforward way to name what we are talking about. Not so long ago, the human rights community dutifully spoke of "the right of everyone to the enjoyment of the highest attainable standard of physical and mental health." Fortunately we have by now exchanged that awkward phrasing for the shorter and simpler phrase "the right to health," without losing sight of the rich complexity of meaning behind this convenient shorthand. The time has come to similarly speak of "the right to science."

This of course still begs the question of what we mean by "science." As with any powerful concept - such as "rights," "equality," or "law" - the word "science" is subject to many different usages. Indeed, this essay intentionally draws upon multiple meanings of the term. Perhaps the best definition I can offer of the term "science" as I use it in this essay would be: the systematic application of the human powers of inquiry, observation, and reason to better understand the world; often, but not necessarily, with the aim of finding ways to improve it. In the broadest sense, the term "science" is a placeholder for the scientific endeavor, the body of knowledge produced by science, and its technological applications. "Science" in this conception includes anthropology and philosophy as much as medicine and engineering. It is broad enough to encompass traditional knowledge systems and other epistemologies foreign to the university. ${ }^{4}$ It also holds room for the efforts of amateurs as well as professional scientists who are highly trained in specific traditions. This approach to the concept of science specifically rejects as too narrow the common usage of the term to refer only to specific branches, disciplines, or methods of modern academic enquiry that are empirical, quantitative, or positivist; for example defining "the sciences" in contrast to "the humanities" or "the arts." Science is a form of human culture, a complex collaborative endeavor of meaning-making and creativity. It inevitably relies upon subjective interpretation and even metaphor, as much as some might like to pretend it can be purely objective, mathematical, or centered in laboratories. ${ }^{5}$ Whether you come to this essay as a philosopher, a lawyer, or a student, or even

\footnotetext{
4 B. DE Sousa Santos (ed.), Cognitive justice in a global world: Prudent knowledges for a decent life, Lantham, Maryland, Rowman \& Littlefield, 2007.

5 D. McCluskey, "The Rhetoric of Economics", Journal of Economic Literature, vol. 31, n 2, 1983, p. 481.
} 
simply an activist who wishes to be thoughtful and reflective about your work, you are in my estimation, a scientist.

\section{Foundational Principles}

This section develops four ideas about the foundational principles underlying the right to science. First, it emphasizes the instrumental and intrinsic value of science - both as a means to a technological end, and as a process or activity in which human beings individually and collectively give expression to an important aspect of our humanity. Second, the discussion juxtaposes three conceptions about the aims of science and argues that the human rights vision requires a prioritization of science in service of humanity. Third, the essay emphasizes the importance of recognizing science and technology as global public goods, to be cultivated and encouraged by States, civil society, and the international community for the benefit of all. Fourth and finally, the discussion highlights attention to the touchstone values of inclusivity and participation, both for conducting the scientific process and for ensuring access to its technological fruits.

\section{A. The Value of Science : Both Instrumental AND INTRINSIC}

Why should science and technology find a place in the international bill of rights? Occasionally, access to science and technology may be fundamental to human survival. This is the case, for example, when we are talking about vital health research, essential medicines, or the technology that supports sanitation services and clean water. These most essential aspects of science and technology, however, are already referenced by other human rights, including the right to health, the right to education, and the right to food. The separate recognition of the right to science implies a further purpose for science well beyond providing for these basic human needs.

The key to uncovering that further purpose lies in looking at the context in which the right to science was enshrined in the international human rights texts. The right to science always appears right beside the right to culture, within the very same article. ${ }^{6}$ These two concepts are deeply intertwined, so much so that I generally prefer to speak of "the right to science and culture" in a unified sense, because there is so much overlap between the scientific and cultural aspects. ${ }^{7}$ In the human rights treaties, the right to science and culture always follows immediately after the right to education. This placement is also significant. Unlike the rights to health, housing, or food, access to science and technology is not usually

${ }^{6}$ Article 27(1) Universal Declaration of Human Rights; article 15(1-4) International Covenant on Economic, Social, and Cultural Rights.

7 L. Shaver, “The Right to Science and Culture”, Wisconsin Law Review, vol. 2010, n 1, 2010, p. 121. 
a matter of life and death. It does, however, go to the heart of what kind of life we live. Like education and culture, science and technology hold particular power to improve human life, raise standards of living and promote other human rights. The rights to education, culture, and science have in common a vision of dignified human life and community engagement that goes well beyond mere survival and security needs. Through education, culture, and science, human beings collaborate to realize values of beauty, creativity, the search for truth, and realization of a better tomorrow.

The value of science then, is not purely instrumental. Yes, science and technology also have significant utilitarian value. They can be deployed to solve social problems and improve our material situation. But there is also a value inherent in the process itself, as with the educational process. Engaging in cultural manifestations such as art, literature, music, and theatre helps us to realize and express parts of our shared humanity, which has value from the perspective of individual development and the shared life of the community. Engaging in scientific discovery and technological innovation does as well. Human beings are naturally curious about our world. We seek to understand it. We seek to solve the problems we perceive in it. This is a beautiful and precious part of the human personality. The right to science envisages the scientific and technological endeavor as a process that every person is entitled to participate in - a collective and collaborative process that can help to unite a frequently fragmented world.

\section{B. Science in Service of Humanity}

Although science will ideally reflect and serve these humane values, it is important to acknowledge that scientific inquiry and technology are not inherently good. They are rather vehicles that will serve whatever values they are guided by, for good or for evil. The international bill of rights is not neutral as to these values. When the international community first came together to recognize and enshrine a right to science in the post-WWII moment, historical circumstances made them keenly aware of the immense harm that can come from the misuse of science. Science in service of authoritarianism had advanced the ends of violence, torture, murder, and genocide. Nazi scientists had declared the biological inferiority of non-Aryan races and provided the ideological support for "social cleansing" campaigns that would target Jews, homosexuals, and the mentally and physically handicapped, among other minority populations. American scientists had perfected the means to annihilate cities through nuclear attack. Fire bombing, chemical gassing, the atom bomb, and many other technologies for mass murder... these were among the fruits borne through the vision of science in service to the State.

Bearing in mind these bitter lessons, the Universal Declaration of Human Rights articulated a decidedly different vision: that of science in service of humanity. A science that is deployed to alleviate human suffering and to improve the human 
condition. A science that is committed to high ethical standards, conducted always in ways that are respectful of other human rights. By enshrining this right in the Declaration and by establishing UNESCO, the international community articulated an alternative vision for scientific and technological development, one which recognizes and honors our common humanity by advancing norms of dignity, equality, and freedom. When these humane values are placed at the heart of the scientific process, it becomes more likely that the resulting applications will enhance, rather than threaten, the enjoyment of the full range of human rights. ${ }^{8}$

\section{Science as a Public Good}

In our own time, however, this vision of science in service to humanity is threatened by a new competing vision: that of science in service of profit. In much of our contemporary public discourse, financial profit and economic growth have come to be seen as both the purpose of science and technological innovation, as well as its primary incentive. This shift in philosophical emphasis corresponds with a decline in public investment in science and increasing support for the privatization of research and the commodification of innovation. To be sure, there are many things that markets and for-profit businesses do more efficiently than governments or the social sector, and private entrepreneurship is an essential pillar of economic welfare and human freedom. Yet the philosophy of science in service of profit seems to me to have the ordering of means and ends backward. Harnessing private enterprise to advance scientific research and technological development is all for the good. But to view scientific research and technological development as the servant to enterprise is to put the cart before the horse, and to unwisely divorce science from its much-needed ethical grounding. Science in service of profit is likely to deliver on its promise of delivering a return on private investment, but it is likely to fail in realizing the larger potential of service to humanity.

What is needed is a renewed political and ethical commitment to the pursuit of science as a public good. To call science a human right is precisely to insist that the supply of scientific knowledge and the development of technology must not be left entirely - or even primarily - to market forces. This is true, in the first instance, because science and technology are dependent upon state support to realize their fullest potential. ${ }^{9}$ Just as important is the need for distributive justice. As with health care and education, there is a moral as well as economic value in making science and technology accessible to all, regardless of any particular individual's ability to pay. To claim the right to science is to insist that both the process and the products of science must be understood as public goods intended for the benefit of all, not merely the already privileged, who are best positioned to purchase access in a marketplace. This implies that scientific and

${ }^{8}$ R. CLAUde, Science in the service of human rights, Philadelphia, Pennsylvania, University of Pennsylvania Press, 2002.

${ }_{9}$ M. Mazzucato, The entrepreneurial state: Debunking public vs. private sector myths, New York, Anthem Press, 2014. 
technological research should be the target of public funding, and that innovation policy should prioritize socially valuable ends and the widespread diffusion of technological benefits, especially to benefit vulnerable populations. Science in pursuit of profit will not accomplish this end; science must be ethically grounded in a vision of service to humanity.

\section{INCLUSIVITY AND PARTICIPATION}

Ensuring that everyone benefits from scientific and technological progress, however, cannot be a top-down effort. Achieving this goal depends instead upon broad participation in the process of science. Because the forces shaping scientific advancement are complex, technological progress is often mystified. To outsiders, it may seem that scientific progress is a natural process that simply "happens." To the casual observer, it may seem that a new technology simply "appears," and a short while later, everyone seems to have one. Scholars in the field of Science and Technology Studies offer an important corrective perspective. This discipline investigates science and technology as products of social processes engaged in by real people. Science and technology, like politics and culture generally, do not proceed inevitably in a predetermined direction. Rather, the path they follow in any particular social and historical context is the product of both the individual choices of scientists and larger social forces. Public policy and legal regulation shape which technologies are pursued and set the conditions under which their spread may be accelerated or delayed. These individual and collective choices can and must be guided by ethical judgments, including a commitment to widespread public benefit.

When these normative choices are obscured or neglected, the scientific process can easily drift from its mission of service to humanity. Technological development may end up catering to only a narrow elite, failing to serve those most in need. The challenge of ensuring that everyone benefits from scientific and technological progress requires broader participation and ethical accountability. The ethical emphasis on participation extends not only to ensuring universal access to the ultimate technological fruits of the scientific endeavor; public participation must also inform the values that guide the scientific process itself. Scientific disciplines and technological fields must ensure that they are truly open to equal participation by women and minority populations. Scientists and technologists should also take up the responsibility to ensure that their work is responsive to social needs, informed by outside perspectives and knowledge, and translated to reach beyond "the ivory tower." As the scientific process is guided by such values, it becomes more and more likely that the technological results will in fact be useful and accessible to all, promoting lives with dignity, especially for the most vulnerable. 


\section{Minimum core content}

So far this essay has offered a view of the right to science as shaped by four foundational principles: recognition of the intrinsic as well as instrumental value of science, an ethical insistence upon science in service of humanity, a political commitment to science as a public good, and an emphasis on the importance of broad participation. The second half of this essay explores what these general principles underlying the right to science imply, in terms of specific legal obligations and policy priorities.

One important tool that scholars and jurists have used to concretize the legal obligations corresponding to various human rights is the concept of "minimum core content." Socioeconomic rights are subject to the logic of "progressive realization" in the context of resource constraints. Yet the Committee on Economic, Social, and Cultural Rights has repeatedly emphasized that it is also possible to identify a "minimum core obligation to ensure the satisfaction of, at the very least, minimum essential levels of each of the rights."10 "Minimum core" approaches to human rights interpretation identify specific standards around which there is widespread agreement, which apply even in contexts of very limited resources, or which a nation's failure to honor will be subject to legal censure. The explicit understanding is that these minimum standards are not meant to limit broader understandings of the right. They serve as a baseline or floor, from which upward movement should be continuously pursued. This "minimum core content" approach has been deployed by juridical bodies such as the Committee on Economic, Social, and Cultural Rights (CESCR) and national courts, as well as by human rights scholars, as a method of translating human rights principles into concrete obligations.

One such scholar Katherine Young, has sought to clarify the concept of minimum core content by delineating multiple possible approaches to defining the minimum core content of a right, each of which has precedent in human rights law and Committee practice. ${ }^{11}$ One approach seeks to locate the "core consensus" content of the right, distinguishing this from marginal aspects of the right, upon which disagreement is to be honored. A second approach seeks to identify the "normative essence" of the right, defining a minimum level of the right that is necessary to honor fundamental principles of dignity, equality, and freedom. The third approach attempts to define "minimum obligations" that States must implement as a matter of priority, or be judged to have violated the right through omission. Each of these approaches has a unique emphasis and offers a unique perspective. Efforts to clarify the right to science should draw on all three of these approaches, ideally with an explicit awareness of their complementarities and limitations.

${ }_{10}$ Committee on Economic, Social and Cultural rights, Report on the Fifth Session, 26 November-14 December 1990, (E/1991/23).

11 K. Young, "The Minimum Core of Economic and Social Rights: A Concept in Search of Content", Yale Journal of International Law, vol. 33, $\mathrm{n}^{\circ}$ 1, 2008, p. 113. 
The sections that follow apply each of these three approaches to help identify minimum core content for the right to science. This discussion will first highlight some problems with utilizing the "core consensus" approach for the right to science. Next I will recommend the "normative essence" approach as a more promising starting point for this particular human right. Finally, the discussion will examine how to translate the right to science into "minimum obligations." The article then concludes with a proposed fourth "pragmatic approach" to defining the minimum core content of the right to science.

\section{A. The “Core Consensus" Approach}

The essence of the "core consensus" approach is to locate a minimum core content of a right upon which there is widespread agreement, whereas debate may still exist at the margins of a right. Young describes the "core consensus" approach as being more positivist in nature, since it looks to State practice to identify areas of agreement. ${ }^{12}$ Because it builds upon consensus, this approach has political advantages for institutions that must carefully tend to their legitimacy. A drawback of this approach is that it may be overly conservative, tending toward the "lowest common denominator," and thereby failing to adequately defend the interests of vulnerable individuals. Normative consensus can shift to become either more or less accommodating of human rights claims; it can also reflect political considerations at odds with human rights norms.

For example, there was long a stable political and juridical consensus in Brazil that all citizens were entitled to receive prescribed medications free of charge. ${ }^{13}$ This consensus went hand-in-hand with an administrative and regulatory structure that emphasized public-sector pharmaceutical research and development and forbade the granting of patents on products important to human health. During international trade negotiations in the 1990s, pharmaceutical industry groups successfully pushed for new international patent rules. As a result, Brazil and many other countries were required to revise their domestic laws to extend patent protection to pharmaceuticals. The prices of medicines have risen significantly as a result, and Brazil's health budgets are now under significant strain. Reflecting this new financial pressure, the political and judicial consensus in favor of free provision of medicines as a basic human right now shows signs of unraveling. ${ }^{14}$

This story of access to medicines illustrates several problematic results of the "core consensus" approach as applied to the right to science. First, the consensus on how to balance patent protection and access to medicines has shifted and

\footnotetext{
12 K. Young, op. cit., pp. 142-144.

13 S. Monica, R. Guise, D. WAng, T. De Campos, "Access to Medicines: Pharmaceutical Patents and the Right to Health", in L. SHAver (ed.), Access to Knowledge in Brazil: New Research on Intellectual Property, Innovation and Development, New Haven, Connecticut, Information Society Project, 2010, p. 103.

14 Ibidem, pp. 103-132.
} 
continues to shift over time...a nd not always in the direction of expanded sensitivity to human rights. Were this discussion of the right to science taking place thirty years ago, we would naturally have pointed out that there was no international consensus in favor of patent protection for pharmaceutical technologies. Yet today there is as a matter of positive law a strong international consensus that patents must be granted in all fields, including pharmaceuticals. This legal consensus has emerged because multinational companies successfully leveraged international trade negotiations to advance their own financial interests... often at the expense of public interests. ${ }^{15}$ It would be a mistake, however, to bless a consensus of State practice produced in this manner with the human rights stamp of approval.

The Brazilian example also highlights a second dynamic: the troubling tendency of an emphasis on consensus to empower restrictive interpretations of human rights. The Venice Statement emphasizes that the right to science is often in tension with intellectual property protections, "which should be managed in accordance with a common responsibility to prevent the unacceptable prioritization of profit for some over benefit for all". ${ }^{16}$ The Special Rapporteur in the field of cultural rights has similarly recommended States to "guard against promoting the privatization of knowledge to an extent that deprives individuals of opportunities to take part in cultural life and enjoy the fruits of scientific progress, and consequently to reconsider the current maximalist intellectual property approach...." ${ }^{17}$ Given the economic value of patent rights to politically powerful actors, however, it is highly unlikely that we will ever observe a consensus in favor of restricting them, no matter how strong the public policy arguments for doing so might be. Emphasizing a consensus approach to defining the minimum core content of the right to science, therefore, could empower powerful groups to successfully oppose recognition of the human rights of the vulnerable.

On the other hand, some aspects of the right to science do already have a stronger consensus behind them. For example, calls to respect academic and scientific freedom, and to enforce safeguards for human research subjects, are ones that admit little disagreement, at least in principle. There is also widespread support in scientific fields for the desirability of open access publishing. Thus in certain areas it may be possible to point to some minimum core content on the basis of a consensus principle. Care must be taken, however, to ensure that the emphasis on consensus does not become a tool for limiting rights, particularly where intellectual property regimes are concerned. The "minimum core" of the right to science should not be confined only to respect for academic freedom and ethical safeguards on research - both of which are already justifiable on other

15 S. Sell, Private Power, Public Law: The Globalization of Intellectual Property Rights, Cambridge, Cambridge University Press, 2003.

16 United Nations Economic, Social and Cultural Organization, Venice Statement on the Right to Enjoy the Benefits of Scientific Progress and its Applications, 16-17 July 2009.

17 Report of the Special Rapporteur on the right to enjoy the benefits of scientific progress and its applications, op. cit. 
human rights grounds, such as freedom of speech and the right to health. The potentially unique contributions of the right to science, for instance in underscoring the need to cultivate scientific knowledge and research as a public good, and addressing the problems of inequitable access to technology, require looking beyond easy consensus.

In sum, the core consensus approach is problematic when it comes to the right to science, because the recently dominant approach to technology policy so relentlessly emphasizes market orientation, privatization, and exclusivity of access-values antithetical to the grounding principles of the right. The right to science is an area of human rights law where the gap between right and reality looms particularly wide. If we seek to locate the right within an existing political consensus, we may miss it entirely. The project must be understood as one of building consensus around the right to science, rather than recognizing and formalizing a consensus already present.

\section{B. The "Normative EsSEnce" ApProAch}

The "normative essence" approach reasons from foundational normative values of dignity, equality, and freedom, to specify a minimum core of each human right that is essential to upholding these values. This may take the form of a "basic needs" emphasis, seeking to define the degree of enjoyment of the right that is necessary and generally sufficient to preserve human life. Or the approach may be more expansive, seeking to guarantee not only survival but also to provide conditions for a broader conception of human flourishing-protecting not just life, but life with dignity. In this second vein, the "human capabilities" approach seeks to define a set of basic entitlements well beyond mere survival, to which every individual has a strong moral claim. Either way, both approaches have in common the desire to specify a degree of enjoyment of the right to which no individual should be denied, which is defined with regard to underlying universal values.

In the area of the right to science, the "normative essence" approach can be applied in several ways.

First, we might define certain "essential technologies" as fundamental to a dignified life, and require States to ensure that these technologies are accessible to all. It would, for example, be easy to place water purification technology, sanitation, and essential medicines on this list. These technologies are understood as important to basic survival. Moving beyond mere survival to include criteria of dignity, equality, and freedom would expand the list of essential technologies further. Electricity, telephone service, and Internet access probably qualify for this more inclusive list of technologies essential for realizing human capabilities. This approach to a minimum core already finds support in the Special Rapporteur's Report on the right to enjoy the benefits of scientific progress and its applications, which has emphasized that: "A core principle is that innovations 
essential for a life with dignity should be accessible to everyone, in particular marginalized populations." 18 The Report recommends that this goal be achieved through consultation to identify the priority needs of marginalized populations for public subsidies and targeted research, ${ }^{19}$ as well as through public utilities to ensure universal access to electricity, telephone, and Internet services. ${ }^{20}$

Second, beyond the emphasis on access to specific technologies - the concrete benefits of scientific progress - the right to science also emphasizes sharing in the process of scientific progress itself. Here, the essential minimum approach points to minimum core content such as access for all to basic scientific education, access to the tools for continually studying the world around them (such as literacy, books, and the Internet), protection of their safety and dignity when they participate as research subjects or are otherwise subjected to new technologies in a context of vulnerability, and consideration of their needs and priorities in shaping the direction of scientific research and technological development. These aspects of minimum core content, too, already find recognition in the Report of the Special Rapporteur.

One virtue of the essential minimum approach to defining a minimum core content is that it works well to focus attention on the basic needs of vulnerable populations. Emphasizing universal access to water and electricity will deliver the greatest benefit to the poorest groups within each society. Yet poverty is not the only dimension of social vulnerability that can be addressed by this approach. From a gender perspective, access to certain technologies can also greatly relieve the disparate psychological, physical, and health burdens placed upon women. Technologies fundamental to gender equality include family planning methods to reduce the health burdens of high-multiples pregnancy, an easily accessible water supply to relieve girls and women of the burden of water-carrying, and modern systems of fuel delivery for cooking food to avoid unhealthy daily exposure to smoke. Women's rights advocates have also pointed out the importance of access to a simple yet often socially taboo technology: the sanitary pad. Women and girls who lack the resources to purchase this modern technology tend to endure shame, miss school, and be socially isolated. Disability advocates could likewise identify certain adaptive technologies as essential to ensuring lives of dignity and equality for persons with special needs.

A unique challenge in applying the "essential minimum" approach to the right to science lies in the special nature of technology as the object of this right. We must take care to guard against two common errors. The first is related to our conception of what counts as technology. The second is related to which technologies

\footnotetext{
18 Report of the Special Rapporteur on the right to enjoy the benefits of scientific progress and its applications, op. cit.

19 Ibidem.

20 Ibidem.
} 
qualify as essential. Both of these pitfalls can tempt us to take too limited a vision of the scope of essential technologies.

First, we must not be too narrow in our concept of what qualifies as technology. There is an incredible gap in the level of access to technology enjoyed by the most privileged sector of humanity and the least privileged sector. This might cause us to conceive of technology too narrowly as only the latest and most "cuttingedge" innovations, such as sophisticated smartphones and gene therapy. The technologies of greatest relevance to vulnerable groups, however, are likely to be much more basic and may even be decades old. I have in mind examples such as indoor electricity for lighting, systems for delivering running water to homes and containing waste, and oral rehydration salts to treat acute gastrointestinal illnesses. These are technologies in the sense that they are tools developed by human ingenuity to solve particular problems. Individually and collectively they have improved and saved many millions of lives. To leverage the right to science in a way that is actually useful for marginalized groups, we will need to be broad and inclusive in our conception of technology, both old and new.

Second, we must resist the temptation to be too stingy in our concept of which technologies are essential. Technology advances, and the list of technologies deemed essential to a life of dignity and freedom must expand accordingly. ${ }^{21}$ It may feel particularly awkward to recognize newer technologies - such as Internet access - as essential ones. After all, until very recently, everyone made do without that particular technology, and we would not say that the lives we led then were lacking in dignity or freedom. But if "the right to enjoy the benefits of scientific progress and its applications" means anything, it is precisely that these new innovations and technologies are to be enjoyed by all. Fifty years ago, we could not have said that there was a universal human right to antiretroviral therapy for HIV infection; neither antiretrovirals nor HIV was known at the time. Yet today it is not difficult to recognize such medicines as an essential innovation from a human rights perspective. ${ }^{22}$

These two cautionary principles operate in a complementary way. The first reminds us not to overlook technologies that might seem too old. The second reminds us not to rule out technologies that might seem too new. An essential technology, from the view of human rights, may be very old or very new. The limiting principle is not the age of the technology, but its importance for promoting human freedom, dignity, and equality.

This last caveat points to one final challenge in applying the "essential minimum" approach to the right to science or any human right: it often remains difficult

\footnotetext{
${ }^{21}$ M. LAND, “Toward an International Law of the Internet”, Harvard International Law Journal, vol. 54, n 2, 2013,

p. 393. $y$ otros vs. MSAS s/amparo. Expediente $\mathrm{N}^{\circ}$. 15.789. Sentencia $\mathrm{N}^{\circ}$. 196. This case recognized access to state of the art HIV medications as required by the right to life, the right to health, and the right to science.
} 
to get very specific in defining the content of the right. To translate the right to science as universal access to essential technologies is to replace a very abstract principle with an only somewhat less abstract one. It still remains to be defined which technologies are essential to dignity, freedom, and equality. It also remains to be defined what exactly States must do to ensure that access, ranging from subsidies for research and commercialization to direct procurement or provision. This remaining ambiguity may be a fault or a virtue. On the negative side, we may be left with less clarity and specificity than had been sought. On the positive side, it may be appropriate to leave this clarification and concretization to domestic processes of advocacy, policy-making, and adjudication, in light of particular national priorities and needs.

\section{The "Minimum Obligations" approach}

In contrast to the "normative essence" and "consensus core" approaches, the "minimum obligations" approach has been more explicitly focused on defining not the right itself, but the corresponding duties of States. This emphasis is intended to make human rights particularly useful for guiding public policy, to facilitate more effective international supervision, and to enable domestic and regional rights adjudication. The "minimum obligations" approach goes handin-hand with the "violations approach" to human rights, which seeks to define human rights and their corresponding State duties specifically enough to enable their justiciability in particular cases. It may also serve as a framework for priority setting in national policymaking and international cooperation. The minimum obligations approach often builds on the normative essence or consensus core approaches, translating the rights identified there into duties, and identifying which corresponding State duties are most appropriate to insist upon. ${ }^{23}$

The "minimum obligations" approach can also be related to the effort to distinguish between positive obligations requiring States to act in certain ways that promote the enjoyment of human rights versus negative obligations requiring States to refrain from activities that would prejudice human rights. A more elaborate three-part approach, conceiving of government duties to respect, protect, and fulfill human rights, is often used to elaborate different ways in which government actions or inactions relate to the right. For example, governments have a duty to respect the right to science by refraining from activities that would interfere with academic freedom. ${ }^{24}$ Mere inaction in respect of the right to science, however, will not go very far to ensuring its enjoyment; active steps are also required. Governments can protect the right to science by ensuring that intellectual property rules are well designed to promote creativity and innovation without unduly sacrificing

\footnotetext{
23 K. Young, op. cit.

${ }^{24}$ Y. DonDERs, "The Right to Enjoy the Benefits of Scientific Progress : in Search of State Obligations in relation to Health", Medicine, Health Care and Philosophy, vol. 14, n 4, 2011, p. 371.
} 
participation and access, ${ }^{25}$ and by using effective regulatory procedures to protect the safety and dignity of human research subjects. ${ }^{26}$ Governments can fulfill the right to science by funding research and development, establishing mechanisms that enhance popular participation in science and providing science education through public schooling and publicly supported media.

Another way to think of the minimum obligations approach is in tandem with the principle of progressive realization. It is well understood that the realization of socioeconomic rights is often significantly constrained by limits on government resources, which differ greatly from country to country. Yet the principle is also well established that certain priority aspects of human rights require immediate implementation by all countries. This may be so because implementation of that priority aspect does not require great resources. Alternatively, even if the resource investment may be substantial, the cost-to-benefit calculus is nevertheless compelling. For example, in the area of the right to housing, minimum obligations include the government duty to respect the right to housing by not conducting illegal evictions. A government can hardly claim that it is too poor to grant due process and consideration for human rights before evicting people from their land or homes. ${ }^{27}$ Minimum obligations with respect to the right to education have similarly been defined to include providing free and universal primary education. ${ }^{28}$ No doubt, significant financial resources must be mobilized to comply with this duty. Yet the normative and utilitarian justifications for universal primary education are so overwhelming that a State's failure to do so simply cannot be reconciled as reasonable priority setting.

Applying this approach, the minimum core content of the right to science would include efforts to expand access to technology and opportunities for scientific participation that are highly cost-effective. Access to clean water, sanitation services, electricity and other essential technologies should be universalized. Academic freedom and Internet freedom should be respected. Technology should not be used in ways that abuse privacy or other human rights. Governments should ensure that intellectual property rules are adopted through a publicly transparent process that allows the concerns of authors and the public to be addressed..$^{29}$ Scientific publications subsidized by government funding should be made available to the public at large, rather than only through private services

\footnotetext{
25 Committee on Economic, Social and Cultural Rights, Statement by the Committee on Economic, Social and Cultural Rights (14 December 2001) (E/C.12/2001/15).

26 Y. DONDERS, op. cit.

27 Committee on Economic, Social and Cultural Rights, Report on the Sixteenth and Seventeenth Sessions, 28 April-16 May 1997, 17 November-5 December 1997, (E/1991/22).

28 Article 13(2)(a) International Covenant on Economic, Social and Cultural Rights.

29 Report of the Special Rapporteur in the field of cultural rights Ms. Farida Shaheed on copyright policy and the right to science and culture, presented at the twenty-eighth session of the Human Rights Council (24 May 2014) (A/HRC/28/57); United Nations Office of the High Commissioner for Human Rights, Independent expert calls for an end to secret negotiations of free trade and investment agreements until public consultation and participation is ensured and independent human rights impact assessments are conducted (30 March 2015).
} 
that restrict public access. ${ }^{30}$ These are just a few examples of highly cost-effective ways of respecting, protecting, and fulfilling the right to science.

\section{A Pragmatic approach}

Katharine Young's work delineating the three major approaches to defining the minimum core content of human rights points out that there are multiple methods and purposes to defining a minimum core. As Young herself suggests, a self-conscious examination of those purposes may help to guide the process. Some familiar motivations for defining a minimum core are to focus public pressure on the most urgent issues, to prioritize the needs of vulnerable populations, to deflate excuses of "limited resources" and "progressive realization," or to advance human rights along the lines most compatible with preserving institutional legitimacy. Bearing these or similar goals in mind, we may work backward to guide our definition of minimum core content in a way that most effectively addresses these needs. Young does not offer a label for this alternative approach to defining a minimum core, but I propose we think of it as a "pragmatic approach" to minimum core content.

In line with this recognition, I suggest that it is natural and appropriate for efforts to elaborate the minimum core content of a right to be responsive to the particular challenges and issues of the time. An emphasis on particular content of urgency today need not limit efforts to recognize and emphasize other aspects of the right in the future, as new needs and challenges are encountered. For instance, the current emphasis on access to essential medicines is an appropriate and necessary response to a particular human rights crisis of our own time: the deaths of millions of people in the prime of their lives from diseases for which effective treatments exist, but which are being denied in the name of intellectual property. A focus today on assuring access to essential medicines today need not mean that the right to science is inherently tied to pharmaceuticals more so than other forms of technology. It is simply the emphasis of a particularly important and timely aspect of the right. The right to science perspective helps to emphasize that the human rights issue is not only one of ensuring universal access to the drugs that exist today, but also reorienting pharmaceutical policy to better meet the needs of vulnerable populations through future research and development.

The arena of copyright law also reveals urgent conflicts between the privatization of knowledge and the right to science. Digital technology today offers the ability to reproduce and share written works at extremely low cost, unimpeded by traditional geographic barriers or the weak state of book publishing and retail in developing countries. We finally have the tools to end the "book famine" that has

${ }^{30}$ Report of the Special Rapporteur in the field of cultural rights Ms. Farida Shaheed on copyright policy and the right to science and culture, op. cit. 
traditionally plagued higher education and scholarly research in many countries of the world. Yet there is a conflict between scholars and students who wish to access these works easily and affordably, and the companies that hold the copyrights in them, who wish to obtain as much revenue as possible. One study calculated that to legally purchase the required readings for the first year of university studies in Brazil would cost six to ten months' income at the minimum wage. ${ }^{31}$ Such a large gap between price and the ability to pay is not sustainable. Solutions must be found that better balance the needs of authors and readers to promote broader access to scientific knowledge.

Also related is the call to require that scientific research be published on an Open Access model, ensuring its ability to be legally distributed and shared. This call responds to the increasing financial pressures faced by academic libraries even at institutions as wealthy as Harvard University. But it is particularly important to the ability of scholars in developing countries to participate in the scientific process. Because academic works in particular are produced according to incentive structures based on university employment, public subsidy, academic reputation, and the individual desire to contribute to shared knowledge, this is an area in which it makes particular sense to emphasize openness and intellectual freedom over treatment as private property. Similarly, Open Access initiatives for primary and secondary textbooks can help address the textbook shortage that critically undermines education in many developing countries, particularly for children from poorer families. These calls have recently found support in the report of the Special Rapporteur on copyright policy and the right to science and culture. ${ }^{32}$

There are also positive developments that need encouragement to be carried forward. The World Intellectual Property Organization (WIPO) recently concluded a treaty designed to expand access to copyrighted works: The Marrakesh Treaty to Facilitate Access to Published Works for Persons Who Are Blind, Visually Impaired, or Otherwise Print Disabled. Previously international treaty-making had focused only on expanding protection for intellectual property. This is the first international instrument designed to ensure that copyright law does not act as a barrier to access and participation. There is great potential in continuing this approach to further advance the right to science. Already debate is underway on international instruments to facilitate additional exceptions and limitations to copyright to assist the work of educational and research institutions and libraries.

The several examples presented above all reflect a common theme. One of the great challenges of our time, to which the right to science must respond, is the privatization of the scientific enterprise and the neglect of public welfare in the name of intellectual property. The emphasis has come to be placed too strongly

\footnotetext{
31 P. Mizukami et al., "Exceptions and Limitations to Copyright in Brazil: A Call for Reform" in L. SHAVer (ed.), Access to Knowledge in Brazil: New Research on Intellectual Property, Innovation and Development, New Haven Connecticut, Information Society Project, 2010, p. 103.

32 Report of the Special Rapporteur in the field of cultural rights Ms. Farida Shaheed on copyright policy and the right to science and culture, op. cit.
} 
on the prioritization of profit and the logic of the market, too often to the neglect of the moral imperative for science to serve human needs. The tendency to regulate intellectual property in the sphere of international trade has aggravated this imbalance. A human rights perspective is urgently needed in this debate. The call to reinvigorate the orientation of the scientific enterprise as a public good in service of humanity and the call to insist upon universal access to the benefits of technology will come from human rights institutions or it will not come at all. The right to science offers a particularly apt and timely framework for reasserting this ethical perspective in the international sphere. Human rights institutions may feel that they have lesser expertise or lesser competency to speak about intellectual property law. That competency must be acquired, just as it was when human rights institutions began to participate in conversations about global public health.

Of course, the challenges of today are not only about intellectual property. The age-old struggle between freedom and despotism continues to play out, in the arena of science and more broadly. Many States are tempted to restrain the academic enterprise or to control their citizens' Internet use as a means to repress political criticism. This too, must be condemned from the perspective of the right to science. We must ensure that the Internet remains a force for promoting freedom, and that controls are not imposed in the name of national security or intellectual property, which will later be abused to restrict the free exchange of ideas. We also continue to face the challenge of expanding access to education, improving its quality at all levels, and protecting academic independence. The right to science can offer a normative framework for guiding respect for intellectual freedom both online and offline.

\section{Conclusion}

By now we are well accustomed to viewing education and health care as public goods, to be publicly supported and made available for the benefit of all. The right to science encourages us to approach science and technology in a similar way. Technology has a great capacity to save and improve lives, when it is directed to those ends. Beyond the utilitarian value of technology, participation in the collective process of scientific and technological development has an intrinsic value as an opportunity to give expression to our human nature, cultivate the human personality, and build international understanding. For both sets of reasons, it is vital that active efforts be taken to ensure that all people enjoy opportunities to participate in the scientific process and benefit from essential technologies, both old and new.

Translating this broad vision of science in service of humanity into minimum core content is both fruitful and challenging. In some areas, such as academic freedom and protection of research subjects, substantial consensus exists on specific 
norms. In other areas, particularly with respect to access to technology, the challenge remains one of building consensus. Indeed, the modern direction of international rulemaking around intellectual property has tended to be one that marginalizes and undermines the right to science, rather than respecting and fulfilling it. Here the problem of pharmaceutical patents and access to essential medicines is merely a particularly high-stakes example of the broader tension between the right to science and intellectual property regimes. This tension presents both a challenge to enjoyment of the right to science and an opportunity for human rights institutions to make a difference. The essence of the right to science is to insist that scientific learning and essential technologies be made available to all. Patent and copyright rules must be designed to strike an appropriate balance between incentivizing innovation and creativity and ensuring broad access to scientific knowledge and new technologies. Public funding must fill the gap to ensure that the needs of marginalized groups are being addressed, despite the necessarily lower profit potential. Leveraging the human rights perspective can help these goals to become a reality.

\section{Lea Shaver}

is Associate Professor of Law at the Indiana University Robert H. McKinney School of Law. She can be reached at lbshaver@iu.edu. 